\title{
Adhesion characterization of tungsten mine waste geopolymeric binder. Influence of OPC concrete substrate surface treatment
}

\author{
Fernando Pacheco-Torgal $^{\text {a,* }}$, J.P. Castro-Gomes ${ }^{\text {b,1 }}$, Said Jalali ${ }^{c, 2}$ \\ ${ }^{a}$ Castelo Branco Polytechnic Institute, Department of Civil Engineering, 6000 Castelo Branco, Portugal \\ ${ }^{\mathrm{b}}$ University of Beira Interior, Department of Civil Engineering, 6200 Covilhã, Portugal \\ ${ }^{\mathrm{c}}$ University of Minho, Department of Civil Engineering, 4800 Guimarães, Portugal
}

Received 12 March 2006; received in revised form 2 September 2006; accepted 6 October 2006

Available online 30 November 2006

\begin{abstract}
Tungsten mine waste mud (TMWM) was investigated for its potential use as repair material of ordinary portland cement (OPC) concrete. Bond strength between OPC concrete substrate and three repair materials was analysed. TMWM geopolymeric binder and two commercial repair products were used as repair materials. Bond strength behaviour was assessed from slant shear tests. A total of 128 slant shear specimens were made in order to evaluate bond strength at 1, 3, 7 and 28 days curing. Four kinds of concrete substrate surface treatment were used, as cast against metallic formwork, as cast against wood formwork, saw cut and acid etching. This study indicates that TMWM geopolymeric binders possess very high bond strength even at early ages and that behaviour is not affected by low surface treatment roughness. Commercial repair products on the other hand show very low bond strength and are very dependent on surface treatment roughness. Scanning electron micrographs reveal that TMWM geopolymeric binders chemically bond to the concrete substrate, while cost comparisons show this geopolymeric repair solution is by far the most cost efficient.
\end{abstract}

(c) 2006 Elsevier Ltd. All rights reserved.

Keywords: Geopolymeric binder; Mine waste; Repair products; Bond strength

\section{Introduction}

Studies of alkali-activated cements have a long history in the former Soviet Union Scandinavia, and Eastern Europe [1]. In 1978, Davidovits created the term "geopolymer", to characterize new materials with the ability to transform, polycondense and adopt a shape rapidly at low temperatures like "polymers" [2]. The polymerization process involves a chemical reaction under highly alkaline conditions on $\mathrm{Al}-\mathrm{Si}$ minerals yielding polymeric $\mathrm{Si}-\mathrm{O}_{-}$ $\mathrm{Al}-\mathrm{O}$ bonds with empirical formula $\mathrm{Mn}\left[-\left(\mathrm{Si}-\mathrm{O}_{2}\right)_{z}-\right.$

\footnotetext{
${ }^{*}$ Corresponding author. Tel.: + 351272 339300; fax: +351 272339399.

E-mail addresses: fernandotorgal@est.ipcb.pt (F. Pacheco-Torgal), castro.gomes@ubi.pt (J.P. Castro-Gomes), said@civil.uminho.pt (S. Jalali).

${ }^{1}$ Tel.: +351275 329990; fax: +351275329969.

${ }^{2}$ Tel.: +351 253 510200; fax: +351253510213.
}

$\mathrm{Al}-\mathrm{O}]_{n} \cdot w \mathrm{H}_{2} \mathrm{O}$, where $n$ is the degree of polymerization, $z$ is 1,2 or 3 , and $\mathrm{M}$ is an alkali cation, such as potassium or sodium [3]. Davidovits reported several advantages of geopolymeric cementitious systems over Portland cement, namely environmental benefits, given that geopolymeric based concrete has a much longer service life than Portland cement based concrete, to greater metals waste encapsulation capacity and lower $\mathrm{CO}_{2}$ emissions, $(0.18$ tonnes of $\mathrm{CO}_{2}$ per tonne of cement [4]). Geopolymerization requires a precursor that contains significant quantities of silicon and aluminium held in an amorphous phase such as ashes from power stations or mining and quarrying wastes.

In Portugal mining and quarrying activities generated $17 \mathrm{Mt}$ of mineral wastes in 2001 which represents $58 \%$ of total industrial wastes. Additionally in order to respect the "Habitats" and "Birds" European Directives [5,6], Portugal has a protected area equivalent to $7 \%$ of the total land area, a value that will soon increase to $22 \%$, due to 
Portugal's recent proposal, under the Natura 2000 Network. This means significant efforts must be made by the scientific community to find alternative uses for mining and quarrying wastes in order to preserve Portuguese protected areas and their natural biodiversity.

Panasqueira is an underground mine situated in central Portugal on the southern edge of the Serra da Estrela mountain range, a natural park, near the Serra do Açor, a protected landscape, and also near the Zezere river. Tungsten and tin have been mined in the Panasqueira area since the 1890s. During the mining process two types of mine waste are generated, coarse aggregates derived from rock blastings and waste mud conveyed by pipelines into lagoons, currently amounting to several million tonnes and still being added almost 100 tonnes per day.

Previous research by the authors shows that in Portugal the production of geopolymeric concrete will be much more expensive than traditional Portland cement concrete due to the cost of the alkaline activators used [7]. However, this cost differential will be reduced in the future when Portland cement costs increase under the European Emissions Trading Scheme. An alternative to using geopolymeric based binders will be to replace high cost materials such as, commercial concrete repair products.

Bond strength is one of the most important properties of concrete repair materials. Bond strength depends not only on the characteristics of the repair material but also on the surface roughness of concrete substrate. Several test methods such as pull-off, splitting, flexural, and slant shear, have been proposed to evaluate the bond properties of repair materials, although they depend on the repair material and on the state of stress of the interface [8,9]. The slant shear test has been adopted in many standards although there are significant differences in specimen dimensions, joint angles and surface preparation [10].The French standard NFP 18-872 [11] uses a prism $(100 \times 100 \times 300)$ sawn at an angle of $60^{\circ}$ to the cross section and repaired by casting fresh concrete or bonding another half-prism of hardened concrete. The Italian standard adopts composite prisms measuring $70 \times 70 \times 200$ with a joint angle of $73^{\circ}$ [12]. According to the ASTM Standard C882-91 [13], the evaluation of bond strength of epoxy systems should be carried out on $76 \times 152$ cylinders of Portland cement mortar made in two halves with the epoxy coat applied to sandblasted or wire-brushed surfaces at $60^{\circ}$ to the cross section. As for the Bs 6319: Part 14 [14] it uses a fractured surface obtained by splitting a $150 \times 150 \times 55 \mathrm{~mm}$ concrete plaque. The plaque is place between a pair of steel plates cut into matching trapezium and the sandwich is mounted between rubber pads in a press. When compression is applied the dilation of the rubber splits the concrete along the line defined by the cuts in the plates. The half-plaques are then repaired and sawn into $150 \times 150 \times 55 \mathrm{~mm}$ test specimens with a complete joint at $60^{\circ}$ to the cross section.

The slant shear test has proven to be a significant test due to the fact that is sensitive to roughness and presents a good correlation with the pull-off test [15]. The test is eco- nomical and can be easily reproduced. The objective of the present work is therefore to investigate bond strength between Ordinary Portland Cement concrete substrate and three repair materials, a TMWM geopolymeric binder and two commercial repair products.

\section{Experimental program}

\subsection{Materials}

\subsubsection{OPC concrete substrate}

The properties of the aggregates used to make the concrete substrates are shown in Table 1. Using the Faury concrete mix design method [16,17], a C30/37 strength class concrete was designed. The concrete mixes and their main properties are described in Table 2. The concrete specimens were cured immersed in water during 3 months. This curing period provides an almost as complete concrete hydration as old concretes in field practice and has been used by other authors [18].

\subsubsection{Current commercial repair products}

Two commercially available repair materials labelled R 1 and R2 were used in this study. Those repair materials are supplied as pre-packed blend of graded aggregates with a maximum size $2 \mathrm{~mm}$, cement, silica fume, fibbers and other additives. The typical density of the fresh material is $2100 \mathrm{~kg} / \mathrm{m}^{3}$. The repair products are ready for on-site

Table 1

Gradation and physical characteristics of aggregates

\begin{tabular}{lcc}
\hline & \multicolumn{2}{c}{ Cumulative percentage retained } \\
\cline { 2 - 3 } & Fine aggregate & Coarse aggregate \\
\hline $9.5 \mathrm{~mm}$ & 0 & 0 \\
$4.76 \mathrm{~mm}$ & 0 & 35.4 \\
$2.38 \mathrm{~mm}$ & 0 & 91.5 \\
$1.19 \mathrm{~mm}$ & 13.9 & 97.2 \\
$590 \mu \mathrm{m}$ & 61.6 & 98.5 \\
$297 \mu \mathrm{m}$ & 97.3 & 99.2 \\
$149 \mu \mathrm{m}$ & 99.7 & 99.4 \\
$74 \mu \mathrm{m}$ & 99.9 & 99.6 \\
Dust content $(<74 \mu \mathrm{m})$ & 0 & 0.4 \\
Fineness modulus & 2.72 & 5.2 \\
Max. dimension $(\mathrm{mm})$ & 2.38 & 9.52 \\
Water absorption $(\%)$ & 0 & 0.4 \\
Density $\left(\mathrm{kg} / \mathrm{m}^{3}\right)$ & 2624 & 2689 \\
\hline
\end{tabular}

Table 2

Mix proportions and main properties of the concrete substrates

\begin{tabular}{lc}
\hline Components & $\mathrm{C} 30 / 37 \mathrm{CPN}$ \\
\hline Cement II $32.5\left(\mathrm{~kg} / \mathrm{m}^{3}\right)$ & 504 \\
Fine river sand & 417 \\
Coarse aggregate & 1154 \\
$\mathrm{~W} / \mathrm{C}$ ratio & 0.43 \\
$\mathrm{fc}_{28 \mathrm{~d}} \mathrm{a}(\mathrm{MPa})$ & 37.8 \\
$\mathrm{ft}_{28 \mathrm{~d}} \mathrm{~b}(\mathrm{MPa})$ & 8.7 \\
\hline
\end{tabular}

${ }^{\mathrm{a}}$ Average value of three specimens $\left(150 \times 150 \times 150 \mathrm{~mm}^{3}\right)$.

${ }^{\mathrm{b}}$ Average value of six specimens $\left(40 \times 40 \times 160 \mathrm{~mm}^{3}\right)$. 
mixing and use, requiring only the addition of clean water. Further data of the repair materials supplied by the manufacturer are as follows:

Material R1 - A water/powder ratio of 0.16 is recommended for use

$\mathrm{fc}_{28 \mathrm{~d}}=45 \mathrm{MPa}, \quad \mathrm{ft}_{28 \mathrm{~d}}=9 \mathrm{MPa}$

Material R2 - A water/powder ratio of 0.14 is recommended for use

$\mathrm{fc}_{28 \mathrm{~d}}=49 \mathrm{MPa}, \quad \mathrm{ft}_{1 \mathrm{~d}}=3 \mathrm{MPa}, \quad \mathrm{ft}_{7 \mathrm{~d}}=6 \mathrm{MPa}$,

$\mathrm{ft}_{28 \mathrm{~d}}=8 \mathrm{MPa}$

\subsubsection{TMWM geopolymeric binder}

The TMWM geopolymeric binder used in this investigation as repair product was made using tungsten mine waste mud previously subject to a thermal treatment at $950{ }^{\circ} \mathrm{C}$ during $2 \mathrm{~h}$, in order to achieve the dehydroxylated state. Mineralogical composition and thermal conditions have been described elsewhere $[19,20]$.

The chemical composition of the mine waste mud is shown in Table 3. The $\mathrm{SiO}_{2} / \mathrm{Al}_{2} \mathrm{O}_{3}$ atomic ratio is 5.5 higher than the one suggested by Davidovits of about 2 for making cement and concrete. However, the final $\mathrm{SiO}_{2} / \mathrm{Al}_{2} \mathrm{O}_{3}$ atomic ratio in the hardened binder depends mainly on the reactivity of $\mathrm{Al}-\mathrm{Si}$ because not all the silica and alumina are reactive, so even despite the fact $\mathrm{Al}$ and $\mathrm{Si}$ have synchro-dissolution behaviour in alkaline solution, meaning they dissolve from the mineral in some linked form one cannot expect the same $\mathrm{Si} / \mathrm{Al}$ ratio in the final hydration product as the one present in the original precursor material. Indeed most of the Al-Si materials cannot even supply sufficient $\mathrm{Si}$ in alkaline solution to start geopolymerization, this explains why they need extra silica provided in solution by waterglass, which influences the $\mathrm{Si}$ / $\mathrm{Al}$ ratio of the hardened binder.

The XRD patterns indicated that mine waste mud consists mainly of muscovite and quartz which were identified by their characteristic patterns as follows: muscovite (card $46-1409$ ) and quartz (card $46-1045$ ). For those thermal conditions XRD patterns indicated that dehydroxylation did not result in a complete collapse of muscovite structure. Calcination leads to formation of an amorphous phase, causing an increase in the general background (BG) of XRD patterns and dominantly taking place in the calcinations interval from 850 to $950{ }^{\circ} \mathrm{C}$, with a thermal behaviour similar to other phyllosilicate clay minerals. The main muscovite peak $\left(2 \theta=8.8^{\circ}\right)$ persisted even after the sample had been heated at $950{ }^{\circ} \mathrm{C}$ although it decreased considerably. Peak area measurements revealed that about $12 \%$ of muscovite survived calcination at $950{ }^{\circ} \mathrm{C}$. Molecular changes during dehydroxylation were also examined with infrared emission spectra (FTIR), confirming decrease in the absorption peaks at 3600-3700 (OH stretch), however, the peak did not disappear totally indicating only a partial transformation.

The geopolymeric binder used was a mixture of coarse aggregates, mine waste mud, calcium hydroxide, alkaline silicate solution and water. The coarse aggregates were the same used in the design of concrete substrate. The mass ratio of coarse aggregates, waste mud: and alkaline activator was 1.5:1:1. Calcium hydroxide was used to replace mine waste mud with a percentage substitution of $10 \%$, because this percentage has been found to lead to the highest compressive strengths [21]. An activator with sodium hydroxide $(24 \mathrm{M})$ and sodium silicate solution $\left(\mathrm{Na}_{2} \mathrm{O}=8.6 \%, \quad \mathrm{SiO}_{2}=27.8 \%, \quad \mathrm{Al}_{2} \mathrm{O}_{3}=0.4 \% \quad\right.$ and water $=63.2 \%$ ) was used with a mass ratio of $1: 2.5$. Previous investigations have show that these conditions lead to the highest long term compressive strength results in alkaliactivated TMWM binders [22]. Distilled water was used to dissolve the sodium hydroxide flakes, to avoid the effect of unknown contaminants in the mixing water. The alkaline activator was prepared prior to use. The sand, mine waste mud and calcium hydroxide were dry mixed before being added to the activator which according to Teixeira-Pinto et al. [23] is the mixing option that leads to the best results. To produce a workable mix extra water has been added as suggested by Jahanian and Rostami [24]. The mass ratio of water/dry solid content was $4 \%$. The compressive and tensile strength of geopolymeric based binder was as follows:

$$
\begin{aligned}
& \mathrm{fc}_{1 \mathrm{~d}}=47 \mathrm{MPa}, \quad \mathrm{fc}_{7 \mathrm{~d}}=60.3 \mathrm{MPa}, \\
& \mathrm{fc}_{14 \mathrm{~d}}=71 \mathrm{MPa}, \quad \mathrm{fc}_{28 \mathrm{~d}}=78.3 \mathrm{MPa} \\
& \mathrm{ft}_{1 \mathrm{~d}}=7 \mathrm{MPa}, \quad \mathrm{ft}_{7 \mathrm{~d}}=11.5 \mathrm{MPa}, \\
& \mathrm{ft}_{14 \mathrm{~d}}=13.6 \mathrm{MPa}, \quad \mathrm{ft}_{28 \mathrm{~d}}=10.7 \mathrm{MPa}
\end{aligned}
$$

Furthermore previous investigations showed that TMWM geopolymeric binder has high abrasion resistance, a C30/37 strength class OPC concrete showed a reduction in weight of $43.6 \%$ after 1000 cycles of abrasion, compared to $13.5 \%$ for TMWM geopolymeric binders. These binders also showed high chemical resistance, when submitted to immersion in a sulphuric acid solution during 4 weeks they had a mass loss of $1 \%$ which compared in a favour manner to a mass loss of $2.6 \%$ for a $\mathrm{C} 30 / 37$ strength class OPC concrete, although the related data have not yet been published.

Another relevant issue about repair materials is their elastic modulus, TMWM geopolymeric mortar specimens have a young modulus between 29.7 and $34 \mathrm{GPa}$ depending

\begin{tabular}{|c|c|c|c|c|c|c|c|c|c|}
\hline $\mathrm{SiO}_{2}$ & $\mathrm{Al}_{2} \mathrm{O}_{3}$ & $\mathrm{Fe}_{2} \mathrm{O}_{3}$ & $\mathrm{~K}_{2} \mathrm{O}$ & $\mathrm{Na}_{2} \mathrm{O}$ & $\mathrm{MgO}$ & $\mathrm{SO}_{4}$ & $\mathrm{TiO}_{2}$ & As & Other minor oxides \\
\hline 53.48 & 16.66 & 12.33 & 7.65 & 0.62 & 1.27 & 3.10 & 1.39 & 1.28 & 2.22 \\
\hline
\end{tabular}
on the type and volume of aggregates used in the execution

Table 3

Chemical composition of TMWM $(\%)$ 
of the mortars, meaning that given the proper amount of aggregates TMWM geopolymeric mortars could have higher young modulus than current OPC concretes as required for efficient repair materials [18].

\subsection{Specimen preparation, bond strength testing and microanalysis}

Bond strength was assessed from a slant shear test. The slant shear test uses square prisms made of two halves, one of the concrete substrate and one of the repair material, tested under axial compression. The adopted geometry for the slant shear specimens was a $50 \times 50 \times 125 \mathrm{~mm}^{3}$ prism with an interface line at $30^{\circ}$ to the vertical (Fig. 1). Bond strength was calculated by dividing the maximum load at failure by the bond area and was obtained from an average of 4 specimens determined at the ages of 1,3 , 7 , and 28 days of curing.

In order to increase the specific surface of the concrete substrate an etching procedure was carried out. The concrete surface was immersed in a 5\% hydrochloric acid solution for $5 \mathrm{~min}$ and then carefully washed to ensure the removal of $\mathrm{CaCl}_{2}$ which results from the reaction between $\mathrm{HCl}$ and $\mathrm{Ca}(\mathrm{OH})_{2}$. According to some researchers this procedure leads to an increase of micro and fine roughness of the concrete substrate [25]. Fig. 2 shows the concrete substrate surface treatment.

The specimens were named after the repair materials and concrete substrate surface treatments. Specimens using concrete substrate repaired with commercial product R1, with surface treatment and with no surface treatment were named respectively, R1-ES (etched surface) and R1-NTS (no treatment surface). Similarly, when the TMWM geopolymer based binder was used to bond the two halves they were named GP-ES and GP-NTS, respectively. Slant specimens with substrate surface treatment as cast against metallic formwork, and as cast against wood formwork were also used repaired with TMWM geopolymeric binder and were named, GP-MF and GP-WF, respectively.

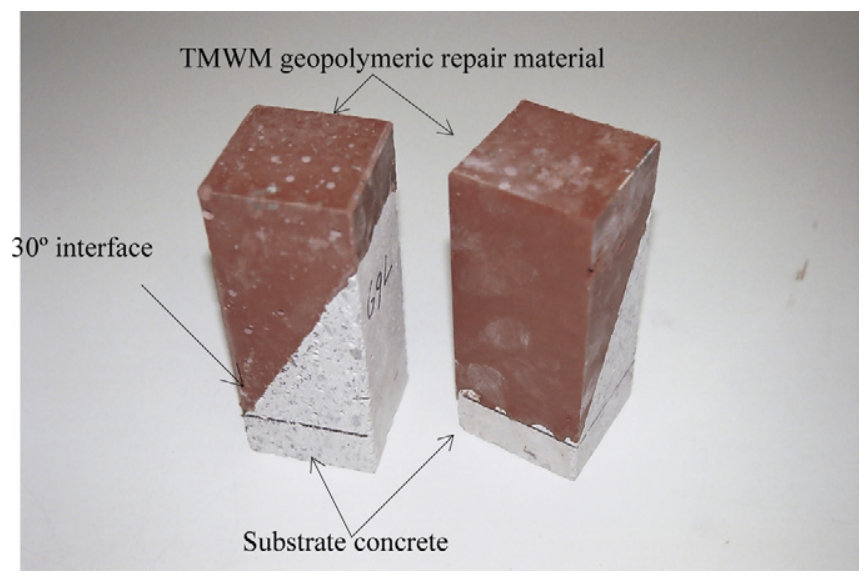

Fig. 1. Slant specimens preparation.
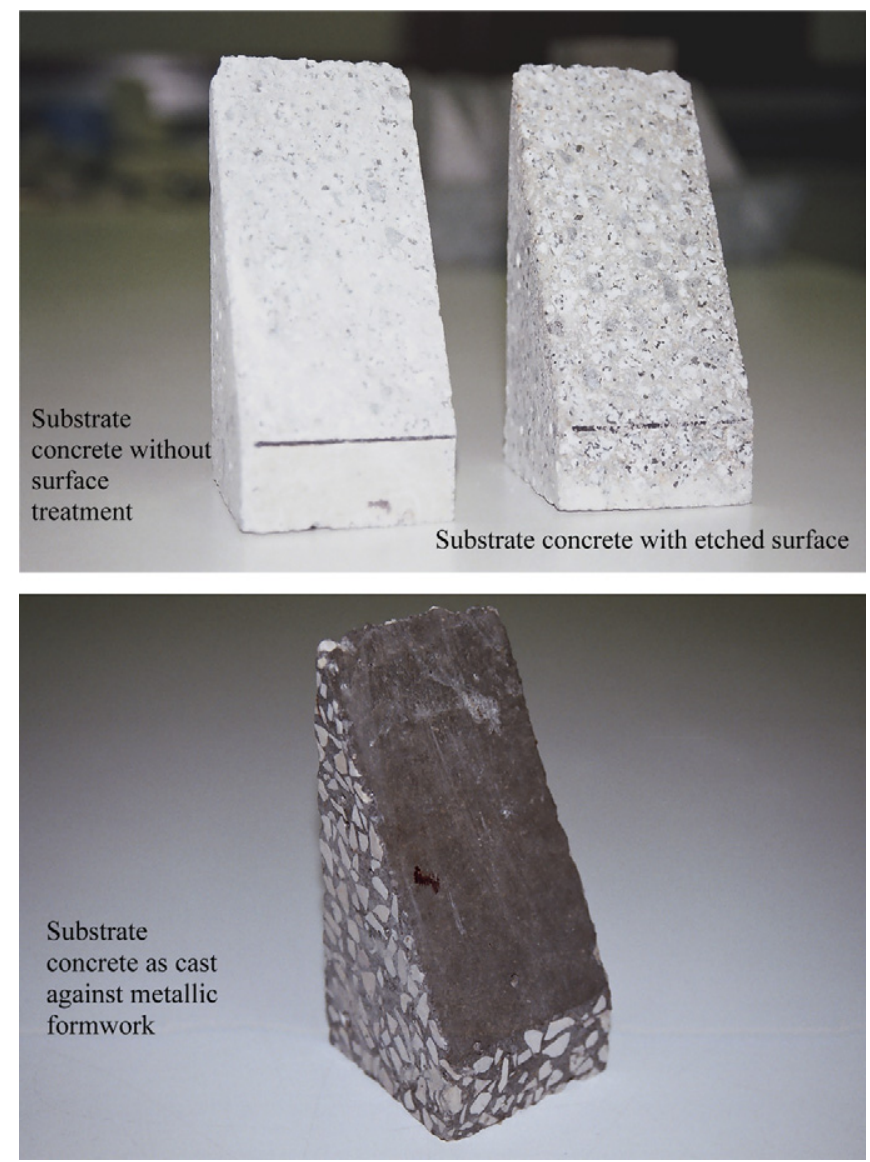

Fig. 2. Slant specimens surface treatment.

For examination by scanning electron microscopy (SEM), the specimens were embedded into a low viscosity epoxy resin, cut and polished. After the lapping stage an additional epoxy impregnation was performed, and the sam-

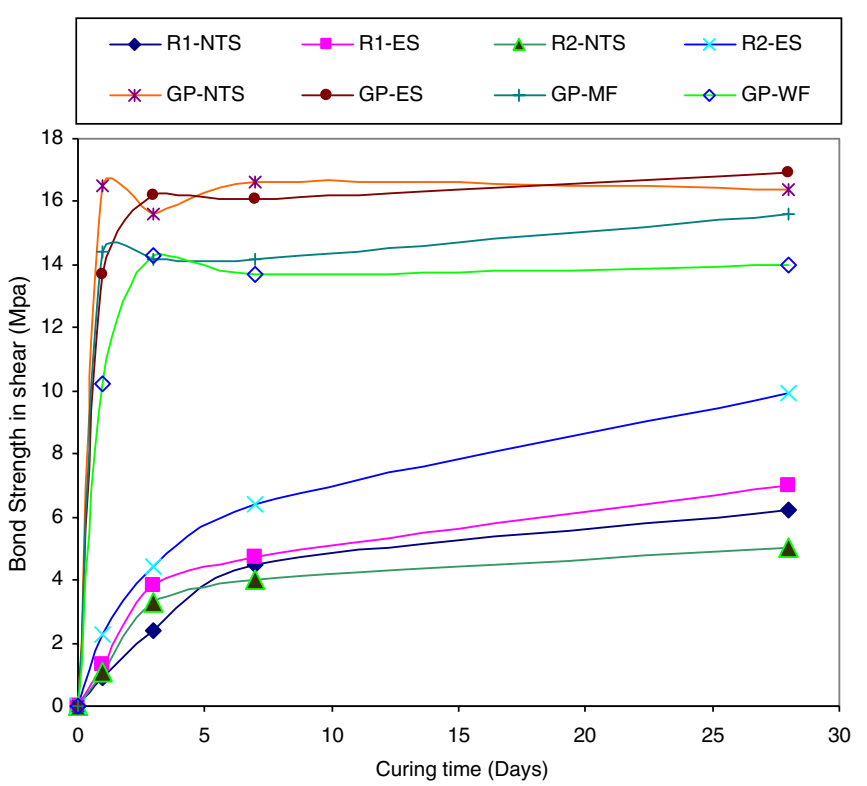

Fig. 3. Slant shear test results. 
ples were relapped in order to ensure full resin impregnation and a good quality polish. The samples were then carboncoated. A Hitachi S2700 scanning electron microscope was used equipped with a solid backscattered detector.

\section{Results and discussion}

The results of the effect of the several repair solutions on average bond strength are shown in Fig. 3. The failure

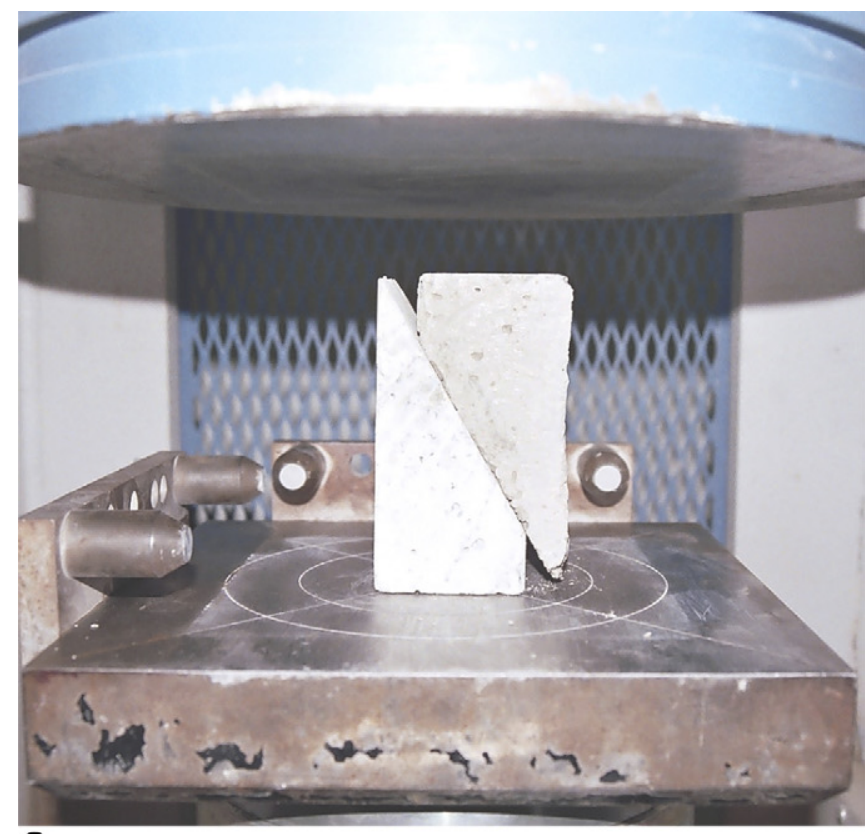

a

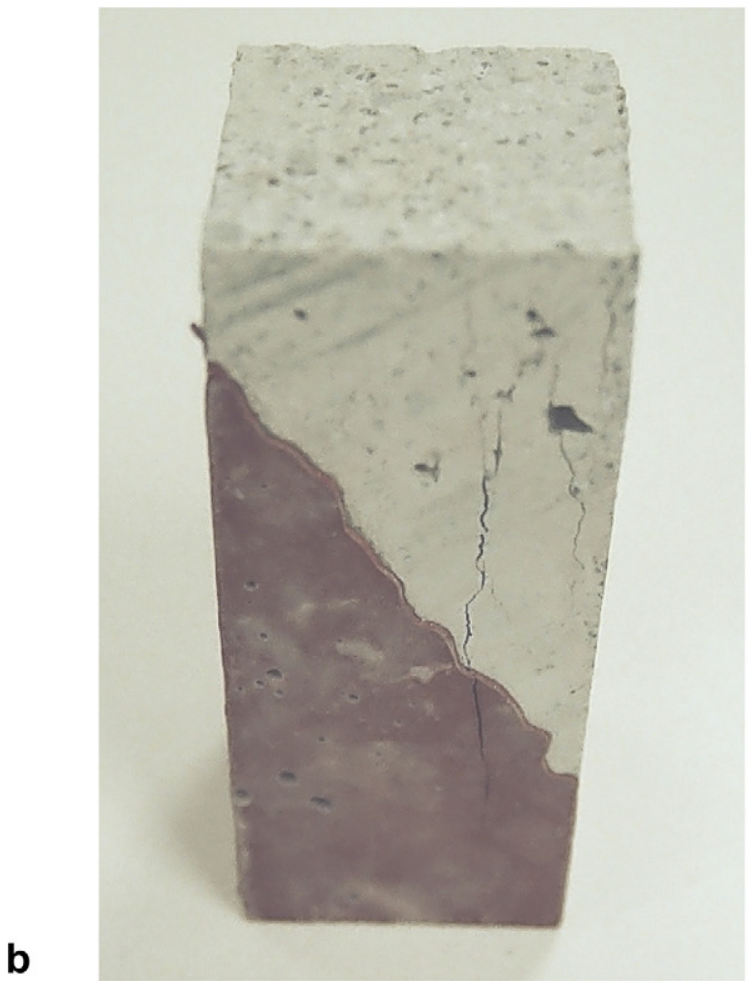

Fig. 4. Slant specimens failure mode: (a) adhesive failure, (b) monolithic failure. modes were characterized by the location of the failure in the slant specimens. An adhesive failure occurs when the plane of failure is along the interface surface (Fig. 4a). Fig. $4 \mathrm{~b}$ shows a slant shear specimen failed in a monolithic failure mode. The values of bond strength in slant specimens with a monolithic failure mode are a lower estimate. It can be seen that the specimens repaired with the TMWM geopolymeric binder present the high bond strength's even at early ages. Specimens repaired with geopolymer binder with 1 day curing have higher bond strength than specimens repaired with current commercial products after 28 days curing. Specimens repaired with the TMWM geopolymeric binder appear to be influenced not by the chemical treatment in sawn concrete surface substrates, but by the use of concrete surfaces as cast against formwork. Those kinds of surfaces are rich in calcium hydroxide but lack exposed coarse aggregates which could contribute to improve bond strength due to silica dissolution from the aggregate surface. This is consistent with previous research by the authors [17]. The strength performance of commercial repair products is very dependent on curing time and this constitutes a serious setback when early bond strength is required. The results show that bond strength using repair product $\mathrm{R} 2$ is clear influenced by the surface treatment.

Table 4 shows the number of specimens that had an adhesive failure. As can be seen, only the slant specimens repaired with the geopolymeric binder and saw concrete substrates present monolithic failures due to is high bond strength. The failure modes for the specimens repaired with current commercial repair products R1 and R2 were iden-

Table 4

Specimens with an adhesive failure

\begin{tabular}{|c|c|c|c|c|c|c|c|c|}
\hline & \multicolumn{8}{|c|}{ Repair material and substrate surface treatment } \\
\hline & \multicolumn{2}{|l|}{$\overline{\mathrm{R} 1}$} & \multicolumn{2}{|l|}{$\mathrm{R} 2$} & \multicolumn{4}{|l|}{ GP } \\
\hline & $\mathrm{ES}$ & NTS & $\overline{\mathrm{ES}}$ & $\overline{\text { NTS }}$ & $\overline{\mathrm{ES}}$ & NTS & MF & $\mathrm{WH}$ \\
\hline \multicolumn{9}{|c|}{ Curing days } \\
\hline 1 & 4 & 4 & 4 & 4 & 2 & 0 & 4 & 4 \\
\hline 3 & 4 & 4 & 4 & 4 & 0 & 0 & 4 & 4 \\
\hline 7 & 4 & 4 & 4 & 4 & 0 & 0 & 4 & 4 \\
\hline 28 & 4 & 4 & 4 & 4 & 0 & 0 & 4 & 4 \\
\hline
\end{tabular}

Table 5

Coefficient of variation of bond strength $(\%)$

\begin{tabular}{|c|c|c|c|c|c|c|c|c|}
\hline & \multicolumn{8}{|c|}{ Repair material and substrate surface treatment } \\
\hline & \multicolumn{2}{|l|}{$\mathrm{R} 1$} & \multicolumn{2}{|l|}{$\mathrm{R} 2$} & \multicolumn{4}{|l|}{ GP } \\
\hline & ES & NTS & ES & NTS & ES & NTS & MF & WF \\
\hline \multicolumn{9}{|c|}{ Curing days } \\
\hline 1 & 23.0 & 33.3 & 21.7 & 27.3 & 6.7 & 6.7 & 12.5 & 14 \\
\hline 3 & 13.1 & 20.8 & 20.4 & 24.2 & 5.6 & 6.4 & 8.4 & 6 \\
\hline 7 & 8.5 & 17.7 & 14.1 & 20.0 & 5.6 & 6.0 & 7.7 & 5 \\
\hline 28 & 10.0 & 16.1 & 12.1 & 16.0 & 6.0 & 6.1 & 7.0 & 1.4 \\
\hline
\end{tabular}


tical and occurred in the interface section, independently of the concrete substrate surface treatment.

Table 5 shows the coefficient of variation (COV) of bond strengths according to curing age. The results show that in all cases, COV decreases with curing age and shear strength increases, except in the case of the specimens repaired with the TMWM geopolymeric binder and with chemical surface treatment (GP-ES). Specimens repaired with current commercial repair products R1 and R2 present very high $\mathrm{COV}$ at early ages. However, after 28 days curing this factor shows acceptable values. For both commercial repair products COV results are clearly influenced by surface treatment. The specimens repaired with the TMWM geopolymeric binder show low COV values even at early ages and are not influenced by the chemical treatment. Comparing COV results in specimens repaired with current commercial repair products with those repaired with the geopolymeric binder, it seems clear that the latter
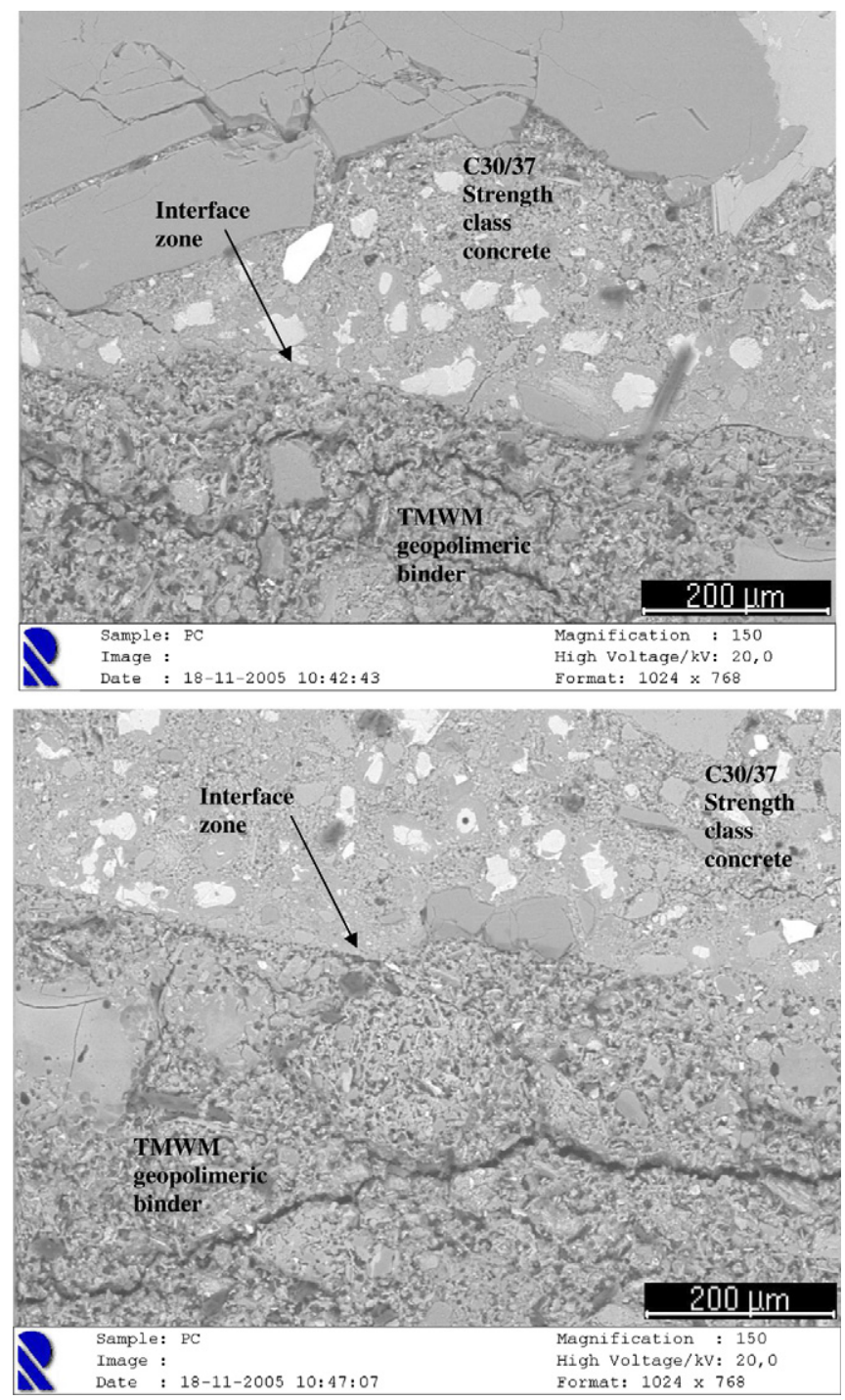

Fig. 5. SEM micrographs of interfacial transition zone between concrete substrate and TMWM geopolymeric binder.

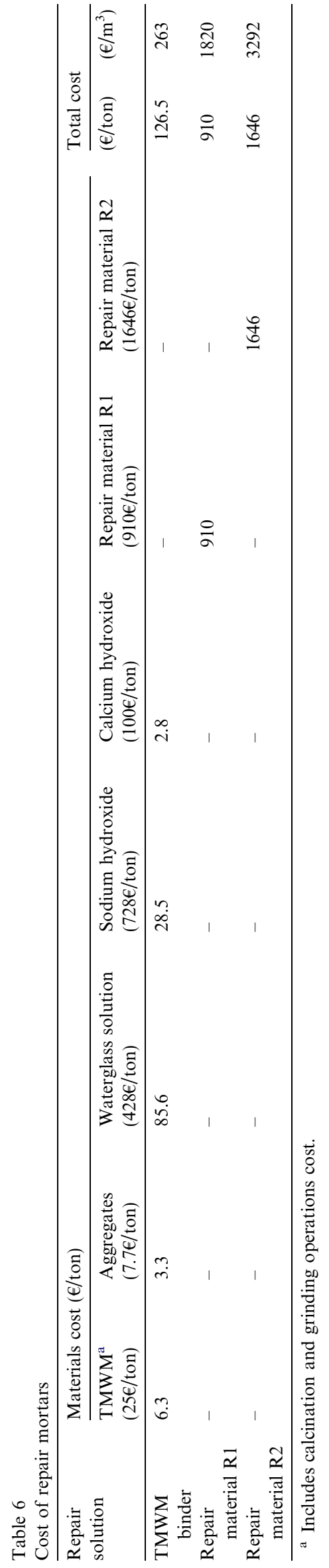




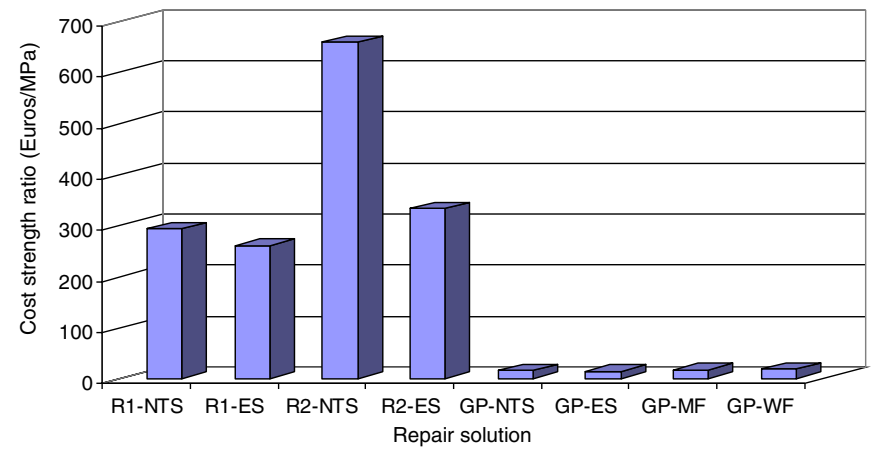

Fig. 6. Cost to strength ratio after 28 days curing according to repair solution.

repair solution is much more reliable. The explanation for this behaviour lies in the fact that OPC concrete substrate surfaces are rich in calcium hydroxide, that reacts to geopolymeric based binders due to the need for positive ions such as $\mathrm{Ca}^{++}$to be present in the framework cavities to balance the negative charge of $\mathrm{Al}^{3+}$ ions and also to the mechanical interlock yield by silica dissolution from aggregate surface when subject to the high alkaline activator. Thus, the concrete substrate chemically bonds to the geopolymeric phase, as it can be seen by the absence of a clear interfacial transition zone on a microstructural level (see Fig. 5).

\section{Cost analysis}

In order to evaluate the economic profitability of the different repair solutions, comparisons between the cost of materials were made. In Table 6 , the cost of the prime materials used to prepare the repair mortars and also of the repair mortars are reported. It must be noted that these values are relative to Portuguese market prices in the year 2005.

Even if the current commercial repair materials had the same mechanical performance of the TMWM geopolymeric binder, the cost of the cheapest one (R1) is still 6.9 times higher than the geopolymeric binder. When comparing the cost to bond strength ratio the differences are even higher, with the cost of the cheapest solution with current commercial repair products (R1-ES) being 13.8 times higher than the solution with TMWM repair binder (see Fig. 6).

\section{Conclusions}

The following conclusions can be drawn from this study:

1. TMWM geopolymeric binder present high bond strength even at early ages. Furthermore bond strength is not affected by low roughness surface treatment of concrete substrate.

2. The strength performance of commercial repair products is very dependent on the curing time and this constitutes a serious setback when early high bond strength is required. The strength of those products also depends on a high level of concrete substrate surface treatment roughness.

3. Cost comparisons between TMWM geopolymeric binder and current commercial repair products show that geopolymeric ones are by far the most cost efficient.

4. In order to evaluate bond durability between concrete and TMWM geopolymeric, accelerated aging environment, such as freeze-thaw cycle acceleration deterioration test should also be carried out.

\section{Acknowledgements}

The writers would like to thank the Optical Centre of University of Beira Interior for helping in SEM investigations.

\section{References}

[1] Roy Della M. Alkali-activated cements. Opportunities and challenges. Cem Concr Res 1999;29:249-54.

[2] Davidovits J. Geopolymers: inorganic polymeric new materials. J Therm Anal 1991;37:1633-56.

[3] J. Davidovits, Chemistry of geopolymeric systems, terminology. In: Proceedings of geopolymer, international conference, France, 1999.

[4] J. Davidovits, Environmentally driven geopolymer cement applications. In: Proceedings of 2002 geopolymer conference, Melbourne, Australia.

[5] Directive (79/409/CEE), Wild birds conservation.

[6] Directive (92/43/CEE), Natural habitats preservation.

[7] Pacheco-Torgal F, Castro-Gomes JP, Jalali S. Portland cement versus geopolymeric binders: economic considerations about the influence of European Emissions Trading Scheme over concrete cost. In: Engineering conference 2005, University of Beira Interior, Covilhã, Portugal, 2005 [in Portuguese].

[8] Austin S, Robins P, Pan Youguang. Shear bond testing of concrete repairs. Cem Concr Res 1999;29:1067-76.

[9] Momayez A, Ehsani MR, Ramezanianpour AA, Rajaie H. Comparison of methods for evaluating bond strength between concrete substrate and repair materials. Cem Concr Res 2005;35:748-57.

[10] Climaco JCTS, Regan PE. Evaluation of bond strength between old and new concrete in structural repairs. Mag Con Res 2001;53: 377-90.

[11] Paillere AM, Rizouliere J. Criteria for evaluation of materials for concrete repair. In: Proceedings of an international conference on Gestion des Ouvrages d'art, vol. 2, Editions Anciens ENPC, 1981. p. 479-84.

[12] Camomilla G. General report. In: Proceedings of an international conference on Gestion des Ouvrages d'art, vol. 2, Editions Anciens ENPC, 1981. p. 105-36.

[13] ASTM C882-91. Standard test method for bond strength of epoxy resin system used with concrete by slant shear, 1991.

[14] British Standards Institution. Testing of resin compositions for use in construction. Method for measurement of bond strength (slant shear method), BS 6319: Part 4, 1984.

[15] Julio ENBS, Branco FAB, Silva VD. Concrete to concrete bond strength. Influence of the roughness of substrate surface. Construct Build Mater 2004;18:675-81.

[16] Faury J Le Beton. Influence de ses constituents inerts. Regles á adopter pour sa meilheure composition. Sa confection et son transport sur les chantier. Paris: Dunod; 1958.

[17] Lourenço Jorge, Coutinho José. Automatic calculations for concrete mix selection. Faury and Bolomey methods. Comissão de Coordenação da Região Centro. Monografias Técnicas, Coimbra, 1986. 
[18] Hassan KE, Brooks JJ, Al-Alawi L. Compatibility of repairmortars with concretein a hot-dry environment. Cem Concr Compos 2001;23:93-101.

[19] Pacheco-Torgal F, Castro-Gomes JP, Jalali S. Alkali activated geopolymeric binder using tungsten mine waste: preliminary investigation. In: Proceedings of geopolymer 2005 world congress, Saint Quentin, France, 2005.

[20] Pacheco-Torgal F, Castro-Gomes JP, Jalali S. Influence of the degree of dehydroxylation of muscovite on the properties of alkali-activated mine waste mud mortars. Strength and Microstructure, unpublished results, 2005.

[21] Pacheco-Torgal F, Castro-Gomes JP, Jalali S. Effect of mix design on the early age strength of alkali-activated mine waste mud mortars. Construct Build Mater, accepted for publication.
[22] Pacheco-Torgal F, Castro-Gomes JP, Jalali S. Effect of aggregates on strength and microstructure of geopolymeric mine waste mud binders. Cem Concr Res, submitted for publication.

[23] Teixeira Pinto A, Fernandes P, Jalali S. Geopolymer manufacture and applications - Main problems when using concrete technology. In: Proceedings of 2002 geopolymer conference, Melbourne, Australia.

[24] Jahanian S, Rostami H. Alkali ash material, a novel material for infrastructure enhancement. Eng Struct 2001;23:736-42.

[25] Xiong G, Cui Y, Chen Liqiang, Jiang Hao. Influence of hydrochloric acid etching on bond strength between concrete substrate and repair materials. Cem Concr Compos 2004;26:41-5. 